\title{
Repurposing celecoxib as a topical antimicrobial agent
}

\author{
Shankar Thangamani, Waleed Younis and Mohamed N. Seleem* \\ Department of Comparative Pathobiology, Purdue University College of Veterinary Medicine, West Lafayette, IN, USA
}

There is an urgent need for new antibiotics and alternative strategies to combat multidrug-resistant bacterial pathogens, which are a growing clinical issue. Repurposing existing approved drugs with known pharmacology and toxicology is an alternative strategy to accelerate antimicrobial research and development. In this study, we show that celecoxib, a marketed inhibitor of cyclooxygenase-2, exhibits broad-spectrum antimicrobial activity against Gram-positive pathogens from a variety of genera, including Staphylococcus, Streptococcus, Listeria, Bacillus, and Mycobacterium, but not against Gram-negative pathogens. However, celecoxib is active against all of the Gram-negative bacteria tested, including strains of, Acinetobacter, and Pseudomonas, when their intrinsic resistance is artificially compromised by outer membrane permeabilizing agents such as colistin. The effect of celecoxib on incorporation of radioactive precursors into macromolecules in Staphylococcus aureus was examined. The primary antimicrobial mechanism of action of celecoxib was the dose-dependent inhibition of RNA, DNA, and protein synthesis. Further, we demonstrate the in vivo efficacy of celecoxib in a methicillin-resistant S. aureus (MRSA) infected Caenorhabditis elegans whole animal model. Topical application of celecoxib (1 and 2\%) significantly reduced the mean bacterial count in a mouse model of MRSA skin infection. Further, celecoxib decreased the levels of all inflammatory cytokines tested, including tumor necrosis factor- $\alpha$, interleukin-6, interleukin-1 beta, and monocyte chemo attractant protein-1 in wounds caused by MRSA infection. Celecoxib also exhibited synergy with many conventional antimicrobials when tested against four clinical isolates of $S$. aureus. Collectively, these results demonstrate that celecoxib alone, or in combination with traditional antimicrobials, has a potential to use as a topical drug for the treatment of bacterial skin infections.

This article was submitted to Antimicrobials, Resistance and Chemotherapy,

a section of the journal

Frontiers in Microbiology

Received: 21 May 2015 Accepted: 08 July 2015 Published: 28 July 2015

Citation:

Thangamani S, Younis W and Seleem MN (2015) Repurposing celecoxib as a topical antimicrobial

Keywords: celecoxib, antimicrobial resistance, repurposing, skin infection, anti-inflammatory

\section{Introduction}

Bacterial infections caused by multi-resistant pathogens have emerged as a major global crisis during the past few decades (Fischbach and Walsh, 2009). The U.S. Centers for Disease Control and Prevention [CDC] (2013) indicated that at least two million individuals per year in the U. S. becomes infected with multidrug-resistant pathogens, including methicillin-resistant Staphylococcus aureus (MRSA), and multidrugresistant Pseudomonas aeruginosa. More importantly, the emergence and spread of multidrug-resistant $S$. aureus clones such as MRSA USA100, USA200, and USA300 are approaching epidemic proportions and becoming a major global health concern 
(Diep et al., 2006; King et al., 2006; Seybold et al., 2006; Davis et al., 2007; Tenover et al., 2008, Tattevin et al., 2009; Tenover and Goering, 2009; Tong et al., 2009; Stryjewski and Corey, 2014). Clones like USA300 are highly virulent and cause skin and soft tissue infections that lead to morbidity and mortality in infected patients (King et al., 2006). Furthermore, the exo-proteins and toxins secreted by these MRSA strains trigger excess host inflammatory responses and further complicate the situation, especially in the management of wound infections (Fournier and Philpott, 2005; Diep et al., 2006, 2012; Gordon and Lowy, 2008). Further complicating the problem, there is increasing incidence of staphylococcal resistance to topical antimicrobials such as mupirocin and fusidic acid (Dobie and Gray, 2004; Kresken et al., 2004; Chambers and Deleo, 2009). Although there are several new approved systemic antibiotics available to treat skin infections such as oritavancin, tedizolid, there is unmet need for novel topical antimicrobial capable of modulating the host immune response and reducing the excessive inflammation associated with bacterial skin infections without exposing the patient to a systemic antibacterial agent.

The development of new antimicrobials is very slow process and has not been able to keep pace with the emergence of bacterial resistance (Fischbach and Walsh, 2009). Hence, novel drugs and treatment strategies are urgently needed to combat these bacterial pathogens. Repurposing of approved drugs is a promising alternative strategy that can accelerate the process of antimicrobial research and development (Rangel-Vega et al., 2015; Thangamani et al., 2015). Unlike conventional drug discovery, finding new uses for existing drugs is a proven shortcut from bench to bedside, that reduces the cost and time associated with antibiotic development (Ashburn and Thor, 2004; Chong and Sullivan, 2007; Rangel-Vega et al., 2015; Thangamani et al., 2015).

Celecoxib (Celebrex) is a non-steroidal anti-inflammatory drug widely used for the treatment of pain, fever, and inflammation (Frampton and Keating, 2007; McCormack, 2011). It specifically inhibits the enzyme cyclooxygenase- 2 (COX2), thereby reducing the synthesis of proinflammatory prostaglandins (Bensen, 2000). Beyond its anti-inflammatory activity, celecoxib has been shown to possess antimicrobial activity against several microbial pathogens. In a study by Pereira et al. (2013) celecoxib was found to reduce the total fungal load in Histoplasma capsulatum infected mice. Further, celecoxib treatment also increased the survival rate of the mice infected with lethal dose of $H$. capsulatum (Pereira et al., 2013). Another study by Chiu et al. (2009) found that celecoxib inhibited the growth of Francisella tularensis and F. novicida. In addition, celecoxib also exhibited antibacterial activity against S. aureus and S. epidermidis (Chiu et al., 2012). Apart from antimicrobial activity, celecoxib inhibits multidrug efflux pumps in Mycobacterium smegmatis and S. aureus, and increases the sensitivity of bacteria to various antibiotics, including ampicillin, kanamycin, ciprofloxacin, and chloramphenicol (Kalle and Rizvi, 2011; Annamanedi and Kalle, 2014). However, the antibacterial mechanism of action of celecoxib and its potential clinical application remain underexplored.

In this study, we investigated the antibacterial activity of celecoxib, as well as the spectrum of its activity against various clinical isolates of multidrug-resistant Gram-positive and Gramnegative pathogens. We also investigated its mechanism of action and validated its in vivo antimicrobial efficacy in two different animal models, including Caenorhabditis elegans and mouse models of MRSA infection. Additionally, we investigated the immunomodulatory activity of celecoxib in a topical application against MRSA skin infection. Finally, we tested the activity of celecoxib in combination with various antimicrobial agents to investigate the potential for synergistic activities.

\section{Materials and Methods}

\section{Bacterial Strains and Reagents}

The bacterial strains used in this study are presented in Tables 1-3. Müller-Hinton Broth (MHB) was purchased from Sigma-Aldrich. Trypticase soy broth (TSB), trypticase soy agar (TSA), and mannitol salt agar (MSA) were purchased from Becton, Dickinson (Cockeysville, MD, USA). Celecoxib was purchased from TSZ chemicals. Vancomycin hydrochloride was obtained from Gold Biotechnology; linezolid from Selleck Chemicals, mupirocin from Aapplichem, NE, clindamycin from

TABLE 1 | Minimum inhibitory concentration (MIC) of celecoxib against Gram-positive bacteria.

\begin{tabular}{|c|c|c|}
\hline Bacteria & Description & Celecoxib $(\mu \mathrm{g} / \mathrm{ml})$ \\
\hline Methicillin-resistant Staphylococcus aureus ATCC 4330 & Clinical isolate resistant to methicillin and oxacillin & 32 \\
\hline Vancomycin-resistant S. aureus (VRSA10) & $\begin{array}{l}\text { Resistant to ciprofloxacin, clindamycin, erythromycin, and } \\
\text { gentamicin }\end{array}$ & 32 \\
\hline Streptococcus pneumoniae ATCC 49619 & Isolated from sputum of 75-year-old male, Phoenix, AZ, USA & 64 \\
\hline Bacillus anthracis & Stern vaccine strain & 16 \\
\hline B. anthracis UM23 & $\begin{array}{l}\text { Weybridge strain which contains the toxigenic } \mathrm{pXO} 1 \text { plasmid and } \\
\text { lacks the pXO2 capsule plasmid }\end{array}$ & 16 \\
\hline B. anthracis AMES35 & $\begin{array}{l}\text { Isolated from 14-month-old heifer that died in Texas in 1981. It is a } \\
\text { derivative of } B \text {. anthracis, strain Ames that was treated with } \\
\text { novobiocin to cure it of the pXO2 plasmid. }\end{array}$ & 16 \\
\hline B. subtilis CU 1065 & - & 16 \\
\hline Listeria monocytogenes & F4244 CDC. Clinical isolate from patient cerebrospinal fluid (CSF) & 32 \\
\hline Mycobacterium smegmatis ATCC 14468 & Reference strain & 16 \\
\hline
\end{tabular}


TABLE 2 | Minimum inhibitory concentration of celecoxib against Gram-negative bacteria.

\begin{tabular}{|c|c|c|c|c|}
\hline \multirow[t]{2}{*}{ Bacteria } & \multirow[t]{2}{*}{ Description } & \multicolumn{3}{|c|}{ MIC of celecoxib $(\mu \mathrm{g} / \mathrm{ml})$} \\
\hline & & $(-)$ & $\begin{array}{l}\text { (+) Sub-inhibitory concentration } \\
\text { of colistin }\end{array}$ & $\begin{array}{l}\text { (+) Sub-inhibitory concentration } \\
\text { of reserpine }\end{array}$ \\
\hline $\begin{array}{l}\text { Pseudomonas aeruginosa } \\
\text { ATCC15442 }\end{array}$ & $\begin{array}{l}\text { Isolated from animal room water } \\
\text { bottle }\end{array}$ & $>256$ & 16 & $>256$ \\
\hline $\begin{array}{l}P \text {. aeruginosa ATCC } \\
\text { BAA-1744 }\end{array}$ & $\begin{array}{l}\text { Clinical isolate and VITEK } 2 \text { GN } \\
\text { identification card quality control } \\
\text { organism }\end{array}$ & $>256$ & 16 & $>256$ \\
\hline $\begin{array}{l}\text { Escherichia coli } \\
\text { O157:H7ATCC } 700728\end{array}$ & $\begin{array}{l}\text { Non-toxigenic and quality control } \\
\text { strain }\end{array}$ & $>256$ & 16 & $>256$ \\
\hline $\begin{array}{l}\text { Acinetobacter baumannii } \\
\text { ATCC BAA1605 }\end{array}$ & $\begin{array}{l}\text { MDR strain isolated from the } \\
\text { sputum of a Canadian soldier }\end{array}$ & $>256$ & 8 & $>256$ \\
\hline $\begin{array}{l}\text { A. baumannii ATCC } \\
\text { BAA747 }\end{array}$ & Human clinical specimen -ear pus & $>256$ & 16 & $>256$ \\
\hline $\begin{array}{l}\text { Salmonella Typhimurium } \\
\text { ATCC } 700720\end{array}$ & $\begin{array}{l}\text { Wild type strain isolated from a } \\
\text { natural source }\end{array}$ & $>256$ & 32 & $>256$ \\
\hline $\begin{array}{l}\text { Klebsiella pneumoniae } \\
\text { ATCC BAA } 2146\end{array}$ & $\begin{array}{l}\text { Clinical isolate New Delhi } \\
\text { Metallo- } \beta \text {-Lactamase (NDM-1) }\end{array}$ & $>256$ & 8 & $>256$ \\
\hline $\begin{array}{l}\text { K. pneumoniae ATCC BAA } \\
1705\end{array}$ & $\begin{array}{l}\text { Clinical isolate with } \\
\text { Carbapenemase (KPC) resistant to } \\
\text { carbapenem }\end{array}$ & $>256$ & 16 & $>256$ \\
\hline E. coli 1411 & Wild type strain & $>256$ & ND & ND \\
\hline E. coli SM1411 $\triangle$ acrAB & Mutant for acrAB efflux pump & 64 & ND & ND \\
\hline
\end{tabular}

TCI Chemicals, and fusidic acid and rifampicin from SigmaAldrich.

\section{Antibacterial Assays}

Minimum inhibitory concentrations (MICs) were determined in triplicate, in Mueller-Hinton broth, using the broth micro dilution method described by the Clinical and Laboratory Standards Institute (CLSI; Mohamed et al., 2014). The MIC was interpreted as the lowest concentration of the drug able to completely inhibit the visible growth of bacteria after incubating plates for at least $16 \mathrm{~h}$ at $37^{\circ} \mathrm{C}$. The highest MIC value taken from two independent experiments was reported.

\section{Gram-Negative Outer Membrane Permeability Assay}

The MIC of celecoxib in the presence of colistin was measured as described in the antibacterial assays section, above. Subinhibitory concentration of colistin $(0.065-0.25 \mu \mathrm{g} / \mathrm{ml}$, Table 2) was added to the media to increase outer membrane permeability and facilitate the entrance of celecoxib. The following subinhibitory concentration of colistin was used; $P$. aeruginosa ATCC15442 and $S$ almonella Typhimurium $(0.25 \mu \mathrm{g} / \mathrm{ml})$, P. aeruginosa ATCC BAA-1744 and Klebsiella pneumoniae $(0.125 \mu \mathrm{g} / \mathrm{ml})$, Escherichia coli O157:H7ATCC 700728 and Acinetobacter baumannii $(0.0625 \mu \mathrm{g} / \mathrm{ml})$.

\section{Effect of Efflux Pump on Celecoxib Activity}

The effect of efflux pumps on the ability of celecoxib to gain entry into Gram-negative bacteria was investigated using known efflux pump inhibitor (reserpine) and efflux pump deletion mutant strain of E. coli. The MIC of celecoxib was examined in the presence of sub-inhibitory concentration of reserpine $(32 \mu \mathrm{g} / \mathrm{ml})$ against all strains of Gram-negative bacteria used in this study. Efflux pump deletion mutant E. coli SM1411 $\triangle a c r A B$ was employed to determine if $a c r A B$ efflux pump plays a role in contributing to intrinsic resistance to celecoxib as described before (O’Neill et al., 2002; Randall et al., 2013).

\section{Time Kill Assay}

The time kill assay was performed as described before (Mohamed et al., 2014). Briefly, MRSA USA300 was diluted to $1 \times 10^{6} \mathrm{CFU} / \mathrm{mL}$ and treated with $4 \mathrm{X}$ MIC of control antimicrobials (vancomycin or linezolid), 4X and 8X MIC of celecoxib (in triplicates) in MHB. Cultures were incubated at $37^{\circ} \mathrm{C}$ and samples were collected at indicated time points to count MRSA colony forming units (CFU).

\section{Macromolecular Synthesis Assay}

Staphylococcus aureus strain ATCC 29213 was grown overnight on TSA plates and the isolated colonies were cultured in $15 \mathrm{ml}$ of $\mathrm{MHB}$ to an early exponential phase $\left(\mathrm{OD}_{600}=0.2-0.3\right)$. Aliquots $(100 \mu \mathrm{l})$ of the early exponential phase culture were added to triplicate wells of a 96-well microtiter plate. Antibiotics with known mechanisms of action (ciprofloxacin, rifampicin, linezolid, vancomycin, and cerulenin) and auranofin were added to the plate as controls. DMSO was added to the control groups. After $30 \mathrm{~min}$ of incubation at $37^{\circ} \mathrm{C}$, radiolabeled precursors such as $[3 \mathrm{H}]$ thymidine $(0.5 \mu \mathrm{Ci}),[3 \mathrm{H}]$ uridine $(0.5 \mu \mathrm{Ci}),[3 \mathrm{H}]$ leucine $(1.0 \mu \mathrm{Ci}),[14 \mathrm{C}] \mathrm{N}$-acetylglucosamine $(0.4 \mu \mathrm{Ci})$, and $[3 \mathrm{H}]$ glycerol $(0.5 \mu \mathrm{Ci})$ were added to quantify the amount of for DNA, RNA, protein, cell wall, and lipid synthesis, respectively. Reactions measuring the inhibition of DNA and RNA synthesis were stopped after $15 \mathrm{~min}$ by the addition of $5 \%$ trichloroacetic acid (TCA). Then, the tubes were chilled on ice for $30 \mathrm{~min}$. 
TABLE 3 | Minimum inhibitory concentration of celecoxib against clinical isolates of S. aureus strains.

\begin{tabular}{|c|c|c|c|c|}
\hline Strain type & Strain ID & Source & Phenotypic properties & Celecoxib $(\mu \mathrm{g} / \mathrm{ml})$ \\
\hline \multirow{22}{*}{$\begin{array}{l}\text { Methicillin resistant } \\
\text { S. aureus (MRSA) }\end{array}$} & USA100 & U. S. $(\mathrm{OH})$ & Resistant to ciprofloxacin, clindamycin, & 32 \\
\hline & & & erythromycin & \\
\hline & USA200 & U. S. (NC) & Resistant to clindamycin, methicillin & 32 \\
\hline & & & erythromycin, gentamicin, & \\
\hline & USA300 & U. S. (MS) & Resistant to erythromycin, methicillin, tetracycline & 32 \\
\hline & USA400 & U. S. (ND) & Resistant to methicillin, tetracycline & 16 \\
\hline & USA500 & U. S. (CT) & Resistant to ciprofloxacin, clindamycin, & 32 \\
\hline & & & erythromycin, gentamicin, & \\
\hline & & & methicillin, tetracycline, trimethoprim & \\
\hline & USA700 & U. S. (LA) & Resistant to erythromycin, methicillin & 32 \\
\hline & USA800 & U. S. (WA) & Resistant to methicillin & 32 \\
\hline & USA1000 & U. S. (VT) & Resistant to erythromycin, methicillin & 32 \\
\hline & USA1100 & U. S. (AL) & Resistant to methicillin & 32 \\
\hline & NRS194 & U. S. (ND) & Resistant to methicillin & 32 \\
\hline & NRS108 & France & Resistant to gentamicin & 32 \\
\hline & NRS119 & U. S. (MA) & Resistant to linezolid & 16 \\
\hline & ATCC 43300 & U. S. (KS) & Resistant to methicillin & 32 \\
\hline & ATCC BAA-44 & Lisbon, Portugal & Multidrug-resistant strain & 32 \\
\hline & NRS70 & Japan & Resistant to erythromycin, clindamycin, spectinomycin & 32 \\
\hline & NRS71 & UK & Resistant to tetracycline, methicillin & 32 \\
\hline & NRS100 & U. S. & Resistant to tetracycline, methicillin & 32 \\
\hline & NRS107 & U.S. & Resistant to methicillin, mupirocin & 32 \\
\hline \multirow{4}{*}{$\begin{array}{l}\text { Vancomycin-intermediate } \\
\text { S. aureus (VISA) }\end{array}$} & NRS1 & Japan & Resistant to aminoglycosides and & 32 \\
\hline & & & tetracycline; glycopeptide- intermediate S. aureus & \\
\hline & NRS19 & U. S. (IL) & Glycopeptide-intermediate S. aureus & 32 \\
\hline & NRS37 & France & Glycopeptide-intermediate S. aureus & 32 \\
\hline Vancomycin-resistant & VRS1 & U.S. & Resistant to vancomycin & 128 \\
\hline \multirow[t]{13}{*}{ S. aureus (VRSA) } & VRS2 & U.S. & Resistant to vancomycin, erythromycin, spectinomycin & 128 \\
\hline & VRS3a & U.S. & Resistant to vancomycin & 32 \\
\hline & VRS3b & U.S. & Resistant to vancomycin & 32 \\
\hline & VRS4 & U.S. & Resistant to vancomycin, erythromycin, spectinomycin & 128 \\
\hline & VRS5 & U. S. & Resistant to vancomycin & 16 \\
\hline & VRS6 & U. S. & Resistant to vancomycin & 16 \\
\hline & VRS7 & U.S. & Resistant to vancomycin, $\beta$-lactams & 128 \\
\hline & VRS8 & U.S. & Resistant to vancomycin & 32 \\
\hline & VRS9 & U.S. & Resistant to vancomycin & 64 \\
\hline & VRS11a & U.S. & Resistant to vancomycin & 32 \\
\hline & VRS11b & U.S. & Resistant to vancomycin & 32 \\
\hline & VRS12 & U.S. & Resistant to vancomycin & 32 \\
\hline & VRS13 & U.S. & Resistant to vancomycin & 32 \\
\hline
\end{tabular}

The TCA-precipitated materials were collected on a $25 \mathrm{~mm}$ GF/1.2 $\mu$ M PES 96-well filter plate. Filters were washed five times with 5\% TCA, dried, and then counted using a Packard Top Count microplate scintillation counter. Reaction wells measuring the inhibition of protein synthesis were stopped after $40 \mathrm{~min}$, precipitated, and counted in a manner similar to that used for the DNA and RNA synthesis inhibition assays. Reaction wells measuring the inhibition of cell wall synthesis were stopped after $40 \mathrm{~min}$ by the addition of $8 \%$ SDS and then heated for $30 \mathrm{~min}$ at $95^{\circ} \mathrm{C}$. After cooling, the material were spotted onto nitrocellulose membrane filters $(0.8 \mu \mathrm{M})$ and washed three times with $0.1 \%$ SDS. Filters were dried and counted using a Beckman LS3801 liquid scintillation counter. Reactions measuring the inhibition of lipid synthesis were stopped after $40 \mathrm{~min}$ by the addition of chloroform/methanol (1:2) and centrifuged at 13,000 rpm for $10 \mathrm{~min}$. Then, the organic phase was carefully transferred to a scintillation vial, dried, and counted using liquid scintillation counting. Incorporation of radiolabeled DNA, RNA, protein, cell wall, and lipid precursors was quantified using the scintillation data and inhibition was calculated. Results were presented as the percent inhibition of each macromolecular synthesis pathway.

\section{Toxicity Assay in C. elegans}

Caenorhabditis elegans AU37 (sek-1; glp-4) strain glp4(bn2) were used for the toxicity studies. L4-stage worms were synchronized as described previously (Alajlouni 
and Seleem, 2013). Synchronized worms ( 20 worms) in 50\% M9 buffer and 50\% TSB were added to each well of a 96-well plate. Drugs (celecoxib and linezolid) at indicated concentrations (16 or $32 \mu \mathrm{g} / \mathrm{ml}$ ) were added to the wells and the plates were incubated for 4 days at room temperature. Worms were assessed every day; the percentage of worms remaining alive in each group was calculated.

\section{Efficacy of Celecoxib in MRSA-Infected C. elegans}

Caenorhabditis elegans AU37 (sek-1; glp-4) strain glp-4(bn2) was used to test the in vivo antimicrobial efficacy of celecoxib as described previously (Alajlouni and Seleem, 2013). S. aureus strain MRSA USA300 was used for infection and the MIC of control antibiotic (linezolid) and celecoxib against MRSA USA300 were 2 and $32 \mu \mathrm{g} / \mathrm{ml}$, respectively. Briefly, L4-stage worms were infected with MRSA USA300 for $8 \mathrm{~h}$ at room temperature. The worms were washed with M9 buffer, and then drugs (celecoxib and linezolid) at indicated concentrations were added to the 96-well plates containing approximately 20 worms per well. After $24 \mathrm{~h}$, the worms were washed four times with PBS and $100 \mathrm{mg}$ of sterile, $1.0-\mathrm{mm}$ silicon carbide particles (Biospec Products, Bartlesville, OK, USA) were added to each tube. Worms were disrupted by vortexing the tubes at maximum speed for $1 \mathrm{~min}$. The final suspension containing MRSA was plated onto MSA plates to count the bacteria. The total CFU count in each well was divided by the number of worms present in the respective well. The results shown are the percent reduction in CFU per worm, compared with an untreated control.

\section{Efficacy of Celecoxib in MRSA-Infected Mice}

Eight-week-old female BALB/c mice (Harlan Laboratories, Indianapolis, IN, USA) were used in this study. All animal procedures were approved by the Purdue University Animal Care and Use Committee (PACUC). The mouse model of MRSA skin infection was performed as described previously (Cho et al., 2010, 2011; Mohamed and Seleem, 2014). Briefly, mice were infected

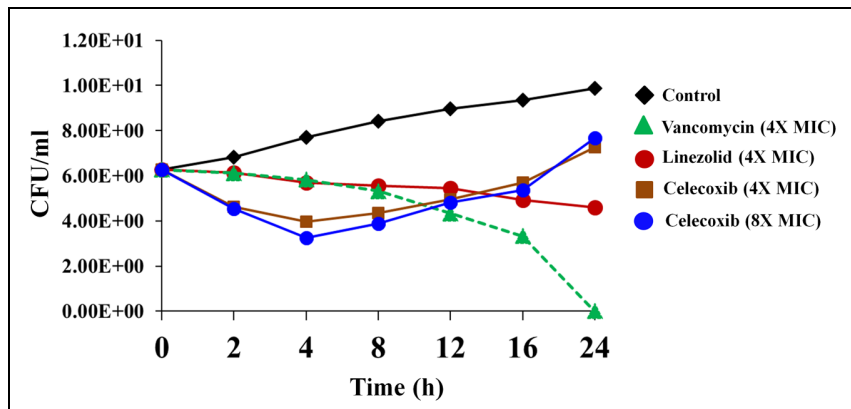

FIGURE 1 | Time-kill assay for celecoxib tested against

Staphylococcus aureus. Killing kinetics of celecoxib (4X and 8X MIC), vancomycin (4X MIC), and linezolid (4X MIC), against methicillin-resistant $S$. aureus (MRSA) USA300 in MHB are shown. The results are presented as means $\pm \mathrm{SD}(n=3)$. Data without error bars indicate that the SD is too small to be seen. intradermally with $1.65 \times 10^{8}$ CFU MRSA300. After $48 \mathrm{~h}$ of infection, open wounds formed and the mice were divided into five groups of five mice each. Two groups were treated topically with $20 \mathrm{mg}$ of either 1 or $2 \%$ celecoxib in petroleum jelly. One group received the vehicles alone (20 mg petroleum jelly). Another group was treated topically with $20 \mathrm{mg}$ of $2 \%$ fusidic acid in petroleum jelly and the last group was treated orally with clindamycin $(25 \mathrm{mg} / \mathrm{kg})$. All groups were treated twice a day for 5 days. $24 \mathrm{~h}$ after the last treatment, the skin area around the wound was swabbed with $70 \%$ ethanol and the wound (around $1 \mathrm{~cm}^{2}$ ) was precisely excised and homogenized. Bacteria in the homogenate were counted using MSA plates.

\section{Determination of Cytokine Levels}

Skin homogenates obtained from infected mice were centrifuged at $4000 \mathrm{rpm}$ for $10 \mathrm{~min}$ and the supernatants were used for the detection of cytokine levels. Tumor necrosis factor- $\alpha$ (TNF- $\alpha$ ), interleukin-6 (IL-6), interleukin-1 beta (IL-1 $\beta$ ), and monocyte chemo attractant protein-1 (MCP-1) ELISA kits (R\&D Systems, Inc.) were used to determine the levels of these cytokines according to the manufacture's instruction (Rioja et al., 2004).

\section{Synergy Assay}

Synergy between celecoxib and conventional antimicrobials (gentamicin, clindamycin, vancomycin, linezolid, daptomycin, retapamulin, fusidic acid, and mupirocin) in the treatment of four clinical isolates of S. aureus (MRSA300, NRS107, NRS119, and VRSA5) was evaluated using the Bliss Independence Model, as described previously (Morones-Ramirez et al., 2013). Synergy (S) was calculated using the formula: $S=\left(f_{A 0} / f_{00}\right)\left(f_{0 B} / f_{00}\right)-\left(f_{A B} / f_{00}\right)$. The parameter $f_{A B}$ refers to the optical density of the bacteria grown in the presence of celecoxib and antibiotics; parameters $f_{A 0}$ and $f_{0 B}$ refer to the bacterial growth rate in the presence of antibiotics alone and celecoxib alone, respectively; the parameter $f_{00}$ refers to the bacterial growth in the absence of drugs. Degree of synergy $(S)$ values corresponds to the following cut-offs: Zero indicates neutral, values above zero (positive value) represents synergism, and values below zero (negative values) correspond to antagonism. Drug combinations with higher positive value represents high degree of synergism.

\section{Statistical Analyses}

Statistical analyses were performed using GraphPad Prism 6.0 software (GraphPad Software, La Jolla, CA, USA). $P$-values were calculated by using two-tailed unpaired Student $t$-tests. $P$-values $<0.05$ were considered significant.

\section{Results}

\section{Antibacterial Activity}

The antibacterial activity of celecoxib was tested using various important multidrug-resistant strains of Gram-positive (Table 1) and Gram-negative (Table 2) pathogens. Celecoxib showed activity against all Gram-positive bacteria tested, including methicillin- and vancomycin-resistant $S$. aureus (VRSA), Streptococcus pneumonia, Listeria monocytogenes, Bacillus 

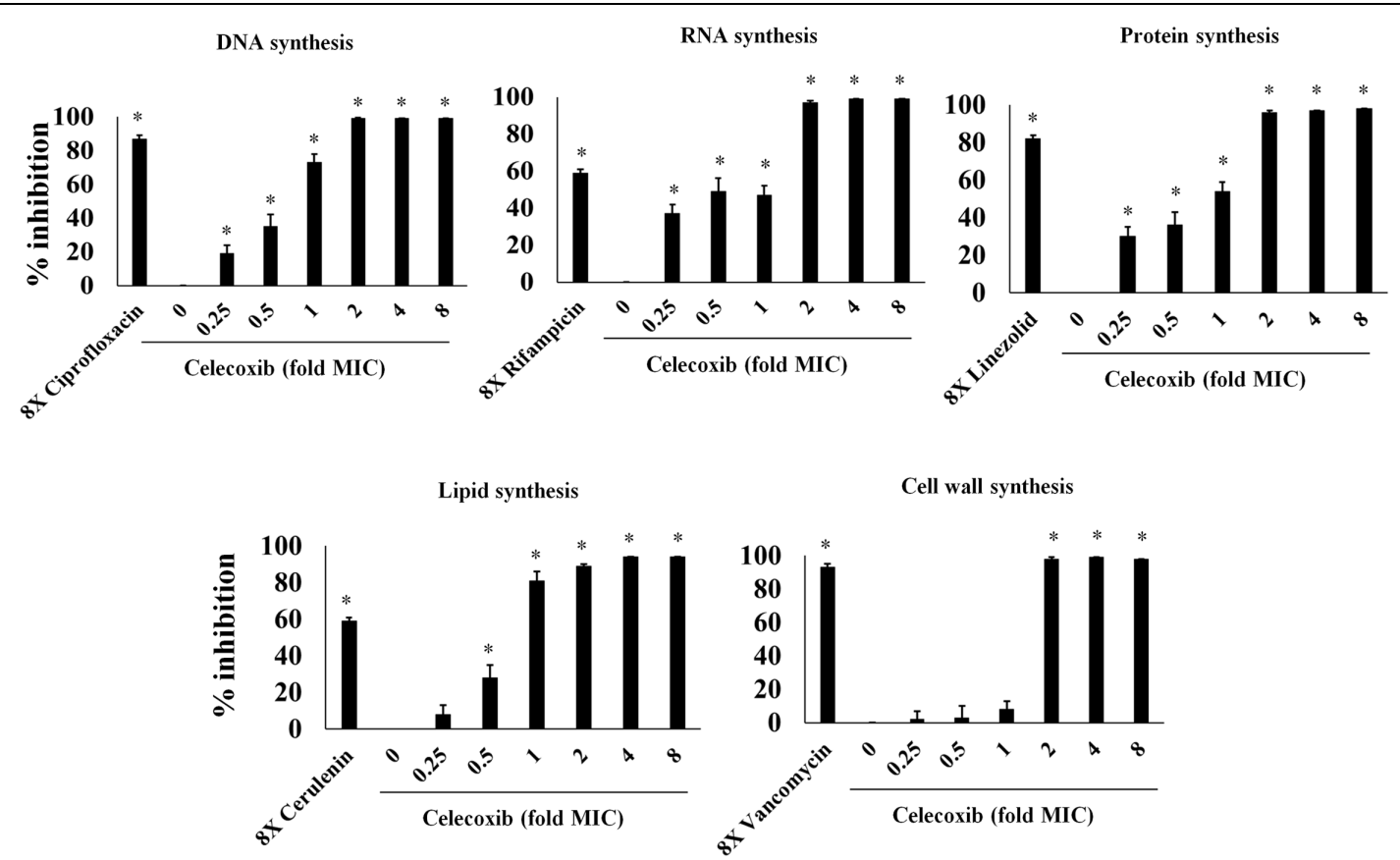

FIGURE 2 | Macromolecular synthesis assay in the presence of celecoxib and control antibiotics. Incorporation of radiolabeled precursors such as [3H] thymidine, [3H] uridine, [3H] leucine, [14C] N-acetylglucosamine and $[3 \mathrm{H}]$ glycerol for DNA, RNA, protein, cell wall, and lipid synthesis, respectively, were quantified in S. aureus ATCC 29213. Based on the incorporation of radiolabeled precursors, percent of inhibition by celecoxib at

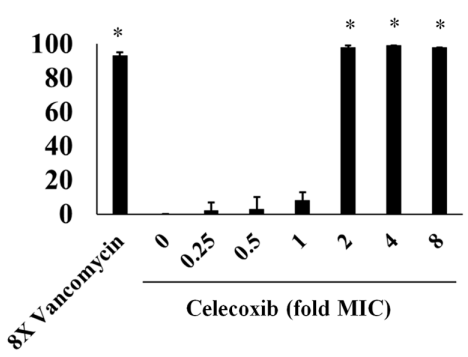

concentration dependent manner was examined. Control antibiotics including ciprofloxacin (DNA), rifampicin (RNA), linezolid (protein), cerulenin (lipid synthesis), and vancomycin (cell wall synthesis) at 8X MIC were used. Triplicate samples were used for each group and the statistical analysis was calculated by the two-tailed Student $t$-test. All treatment groups were compared to untreated control group. $P$-value of $\left({ }^{*} P \leq 0.05\right)$ is considered as significant.

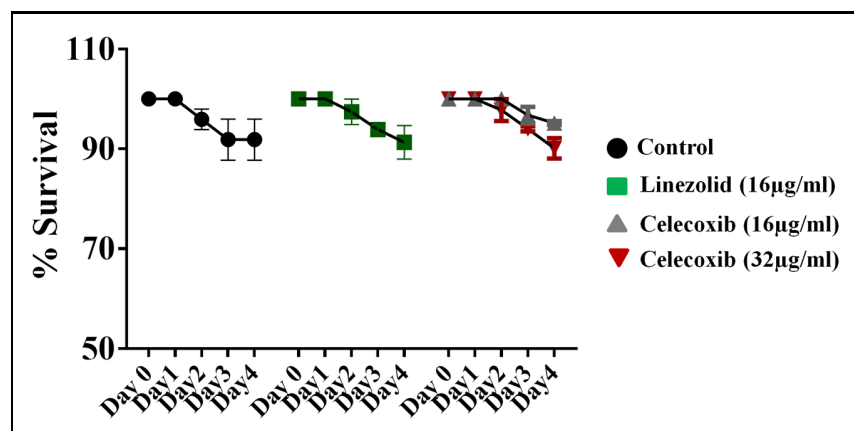

FIGURE 3 | Evaluation of toxicity in Caenorhabditis elegans model. C. elegans strain glp-4; sek-1 (L4-stage) were grown for four days in the presence of celecoxib (16 and $32 \mu \mathrm{g} / \mathrm{ml}$ ) and linezolid $(16 \mu \mathrm{g} / \mathrm{ml})$. Worms were monitored daily and the live worms were counted. Results were expressed as percent live worms in relative to the untreated control groups. Triplicate wells were used for each group and the results were means $\pm \operatorname{SD}(n=3)$.

anthracis, B. subtilis, and M. smegmatis, with MICs ranging from 16 to $64 \mu \mathrm{g} / \mathrm{ml}$ (Table 1). In contrast, celecoxib alone did not show antibacterial activity against Gram-negative bacteria. However, when the outer membranes of Gram-negative bacteria were compromised with a sub-inhibitory concentration of colistin, celecoxib showed antimicrobial activity against all Gram-negative pathogens tested, including P. aeruginosa, E. coli, K. pneumonia, S. Typhimurium, A. baumannii, with MICs ranging from 8 to $32 \mu \mathrm{g} / \mathrm{ml}$ (Table 2). In addition, there was a fourfold decrease in celecoxib's MIC observed in an acrAB mutant E. coli as compared to the wild type strain. We did not observe any change in the MIC with addition of the efflux pump inhibitors reserpine (Table 2).

The antibacterial activity of celecoxib was also assessed using a series of multidrug-resistant $S$. aureus clinical isolates (Table 3). The MIC of celecoxib required to inhibit 90\% (MIC 90 ) of the MRSA and vancomycin-intermediate S. aureus (VISA) clinical isolates was found to be $32 \mu \mathrm{g} / \mathrm{ml}$. However, the $\mathrm{MIC}_{90}$ of celecoxib against VRSA clinical isolates tested was $128 \mu \mathrm{g} / \mathrm{ml}$.

\section{Killing Kinetics of S. aureus by Celecoxib}

We investigated the rate of bacterial killing by celecoxib. As seen in Figure 1, MRSA USA300 treated with $4 \mathrm{X}$ and $8 \mathrm{X}$ MIC of celecoxib exhibits a biphasic killing pattern. Treatment with celecoxib consists of an initial rapid bactericidal phase $\left(2.49 \pm 0.23 \log _{10}\right.$ and $3.01 \pm 0.26 \log _{10}$ CFU reduction at $4 \mathrm{~h}$ with $4 \mathrm{X}$ and $8 \mathrm{X} \mathrm{MIC}$ ) followed by a regrowth of MRSA. In comparison, vancomycin had a bactericidal activity after $24 \mathrm{~h}$, while linezolid treatment results in single log reduction after $24 \mathrm{~h}$ incubation exhibiting a bacteriostatic activity.

\section{Mechanism of Action}

In view of the results demonstrating broad-spectrum antibacterial activity, we used macromolecular synthesis assays in S. aureus ATCC 29213 to investigate the antibacterial 
mode of action of celecoxib. As shown in Figure 2, RNA, DNA, and protein synthesis inhibition were detected at concentrations significantly below the MIC $(0.25 \mathrm{X})$. However, a secondary effect was also observed at higher concentration, with a clear dose-dependent disruption of $[3 \mathrm{H}]$ glycerol incorporation indicating decreased lipid synthesis. Cell wall synthesis inhibition was evident only at a concentration above the $\operatorname{MIC}(2 \mathrm{X})$.

\section{Toxicity in C. elegans}

The safety of celecoxib was evaluated in a $C$. elegans wholeanimal model. As shown in Figure 3, C. elegans treated with 16 or $32 \mu \mathrm{g} / \mathrm{ml}$ of celecoxib for 4 days did not show any significant toxicity. These results are similar to those seen in the linezolid $(16 \mu \mathrm{g} / \mathrm{ml})$ and untreated control groups.

\section{Efficacy in Animal Models}

Having demonstrated a comfortable safety profile, the antibacterial efficacy of celecoxib was tested in a C. elegans, whole-animal MRSA infection model. As seen in Figure 4A, celecoxib treatment significantly reduced the mean bacterial count, compared with the untreated control. Treatment with celecoxib at 16 and $32 \mu \mathrm{g} / \mathrm{ml}$ significantly decreased the bacterial CFU of $0.56 \pm 0.33 \log _{10}$ and $0.94 \pm 0.43 \log _{10}$, respectively. For comparison, linezolid at $16 \mu \mathrm{g} / \mathrm{ml}$ had significant reduction in bacterial CFU $\left(0.99 \pm 0.17 \log _{10}\right)$, compared with the untreated control.

Next we tested the in vivo antibacterial efficacy of celecoxib in a mouse model of MRSA skin infection. As shown in Figure 4B, all treatment groups ( 1 or $2 \%$ celecoxib, $2 \%$ fusidic acid, or clindamycin oral treatment) significantly reduced the mean bacterial counts, compared with the control group $(P \leq 0.05)$. Groups treated topically with 1 and $2 \%$ celecoxib had a reduction in MRSA CFU of $0.66 \pm 0.19 \log _{10}$ and $1.02 \pm 0.27 \log _{10}$, respectively. Topical treatment with $2 \%$ fusidic acid and oral clindamycin $(25 \mathrm{mg} / \mathrm{kg})$ treatment reduced the bacterial load of $2.90 \pm 0.23 \log _{10}$ and $2.40 \pm 0.32 \log _{10}$ CFU, respectively.

\section{Effect of Celecoxib on Inflammatory Cytokine Levels Induced by MRSA Skin Infection}

We investigated the immune-modulatory activity of celecoxib in MRSA skin infection by measuring the levels of the inflammatory cytokines IL-6, TNF- $\alpha$, IL-1 $\beta$, and MCP-1 using ELISA. As shown in Figure 5, treatment with $2 \%$ celecoxib significantly reduced the levels of all tested inflammatory cytokines, compared with an untreated control. Treatment with $1 \%$ celecoxib significantly reduced the levels of IL- 6 and IL- $1 \beta$. Clindamycin treatment also reduced levels of TNF- $\alpha$ and IL- $1 \beta$.

\section{Synergism with Topical and Systemic Antimicrobials}

The antimicrobial activities of combinations of celecoxib with topical and systemic antimicrobials were investigated in vitro, using the Bliss independence model, with clinical isolates of multidrug-resistant $S$. aureus. Celecoxib acted synergistically with all tested antimicrobials (with the exception of linezolid) against all strains of multi-drug resistant $S$. aureus tested, including MRSA300, VRSA5, linezolid-resistant $S$. aureus (NRS119), and mupirocin-resistant S. aureus (NRS107). However, celecoxib showed slight antagonism when combined with linezolid against VRSA5 (Figure 6).

\section{Discussion}

The emergence of bacterial resistance is not a new phenomenon. However, because only a few antibiotics have been developed over the past few decades, the continuous evolution and spread of multidrug-resistant bacterial strains is a serious threat to the public health (Centers for Disease Control and Prevention [CDC], 2013). The pharmaceutical companies' lack of interest in antimicrobial research and development has also become a major concern (Thangamani et al., 2015). The World Health Organization has already warned that we are heading toward a "post-antibiotic era" and suggested that urgent measures need to be taken (Aryee and Price, 2015). Therefore, recent research had been directed toward finding new antimicrobials and novel strategies to combat multidrugresistant bacterial pathogens. One promising approach gaining increased attention is the repurposing of existing approved drugs as antimicrobials.

In an attempt to repurpose approved drugs, we and others (Chiu et al., 2009, 2012; Pereira et al., 2013) have found that celecoxib exhibits broad-spectrum antimicrobial activity against Gram-positive and Gram-negative bacterial pathogens. Celecoxib, a classical Non-steroidal anti-inflammatory drug (NSAID) and inhibitor of the enzyme COX2, has been widely used as an anti-inflammatory drug for the treatment of acute pain, arthritis, menstrual pain, and discomfort (Tindall, 1999; Bensen, 2000; Kumar et al., 2013). Independent of its antiinflammatory action, celecoxib exhibits antimicrobial activity against F. tularensis and S. aureus (Chiu et al., 2009, 2012). Celecoxib also reduces $H$. capsulatum burden by enhancing phagocytosis of alveolar macrophages and decreasing levels of inflammatory cells and cytokines, thereby exhibiting a protective role in pathogenesis of $H$. capsulatum (Pereira et al., 2013). Our study demonstrated that celecoxib possesses activity against various multidrug-resistant Gram-positive bacteria, including S. aureus, S. pneumonia, L. monocytogenes, B. anthracis, B. subtilis, and $M$. smegmatis. However, we noticed that Gramnegative pathogens are not susceptible to celecoxib, and the lack of activity was found to be due to the permeability barrier conferred by the outer membrane. This was further confirmed by the fact that the antimicrobial activity of celecoxib against Gram-negative bacteria was restored when the integrity of the outer membrane was compromised using a sub-inhibitory concentration of colistin (Vaara, 2010; Vaara et al., 2010; Velkov et al., 2013). In addition, celecoxib also showed activity when an efflux pump such as $a c r A B$ was deleted in E. coli. AcrAB has been known to contribute for resistant phenotype for various antibiotics including ampicillin, chloramphenicol, and rifampicin (Okusu et al., 1996). Taken together, in addition to the intrinsic physical barrier outer membrane, celecoxib entry 


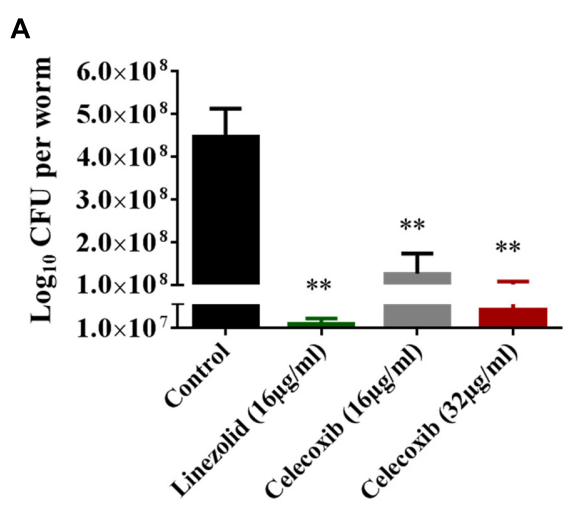

B

FIGURE 4 | Efficacy of celecoxib in MRSA-infected animal models.

(A) L4-stage worms infected with MRSA USA300 were treated with celecoxib ( 16 and $32 \mu \mathrm{g} / \mathrm{ml}$ ) and linezolid $(16 \mu \mathrm{g} / \mathrm{ml}$ ) for $24 \mathrm{~h}$. At this point, the worms were disrupted and the amount of MRSA in the lysate (CFU) was determined. CFU per worm in treated groups relative to the untreated control groups were shown. Triplicate wells were used for each group and the results were

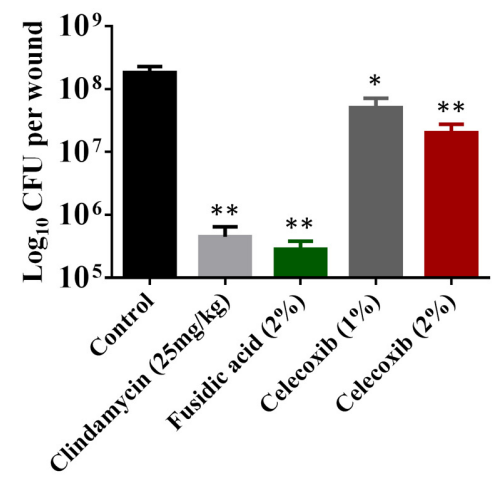

means $\pm \mathrm{SD}(n=3)$. (B) Efficacy of treatment of MRSA-infected mouse skin lesions with celecoxib 1 and $2 \%$, clindamycin (25 mg/ $\mathrm{kg}$ ), fusidic acid $2 \%$, and petroleum jelly (negative control) twice daily for 5 days were evaluated. Five mice per group was used and the results were means \pm SD of five mice. CFU per wound was calculated and presented. ${ }^{*} P \leq 0.05$ and ${ }^{* *} P \leq 0.01$ were considered as significant.

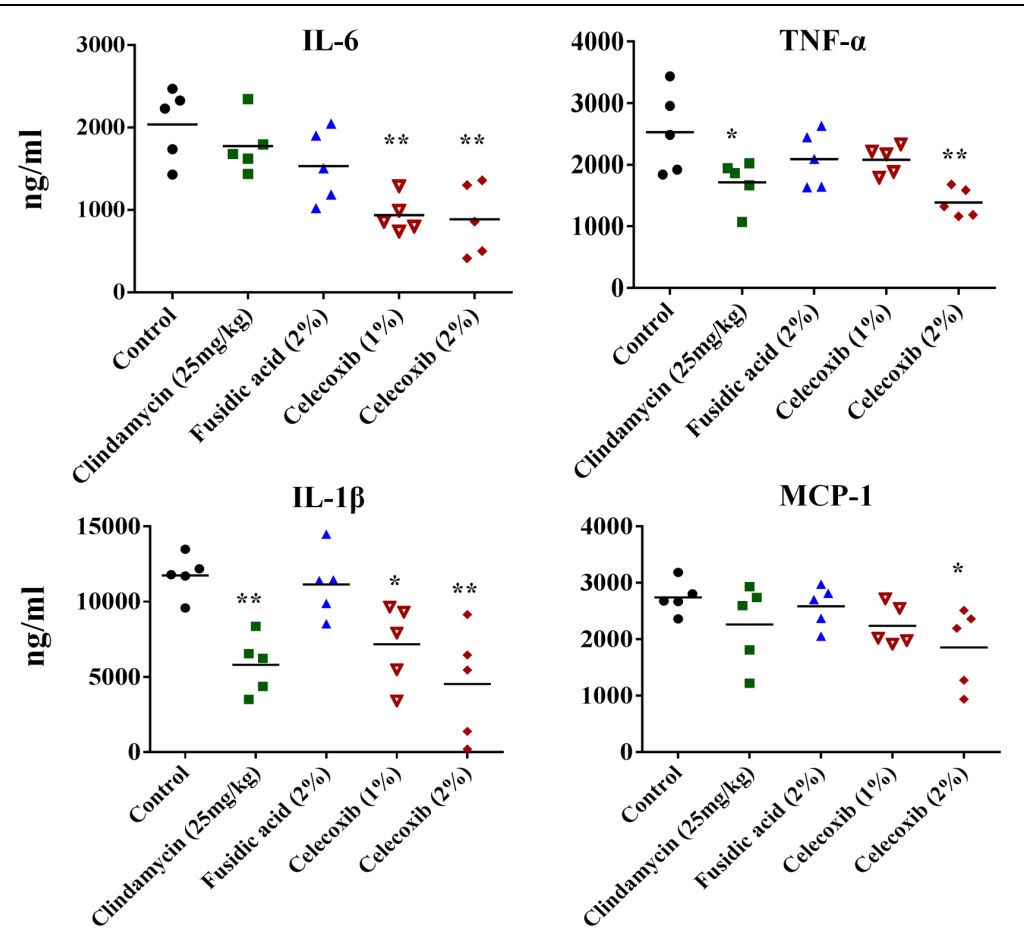

FIGURE 5 | Effect of celecoxib on IL-6, TNF- $\alpha$, IL-1 $\beta$, and MCP-1 production in MRSA infected skin lesions. Supernatants from skin homogenates were used for cytokine detection by ELISA. Each point represents single mice and each group has five mice. Statistical analysis was calculated by the two-tailed Student's t-test. $P$-values of $* P \leq 0.05,{ }^{*} P \leq 0.01$ are considered as significant.

into Gram-negative bacteria is also influenced by efflux pumps such as AcrAB. Our results indicate that the target of celecoxib is present in both Gram-positive and Gram-negative bacteria and that celecoxib can be combined with other approved drugs that cause leakage in the outer membrane, such as colistin, to sensitize Gram-negative pathogens. Next, we investigated the activity of celecoxib against clinical isolates of multidrug-resistant
$S$. aureus. Celecoxib inhibited the growth of all tested clinical isolates of MRSA, VISA, VRSA, linezolid-resistant S. aureus (NRS119), and mupirocin-resistant S. aureus (NRS107). MIC values determined in our study for celecoxib against MRSA correlates with MIC values reported for celecoxib against F. tularensis and S. aureus in previous published studies (Chiu et al., 2009, 2012). 
Methicillin-resistant S. aureus (MRSA 300)

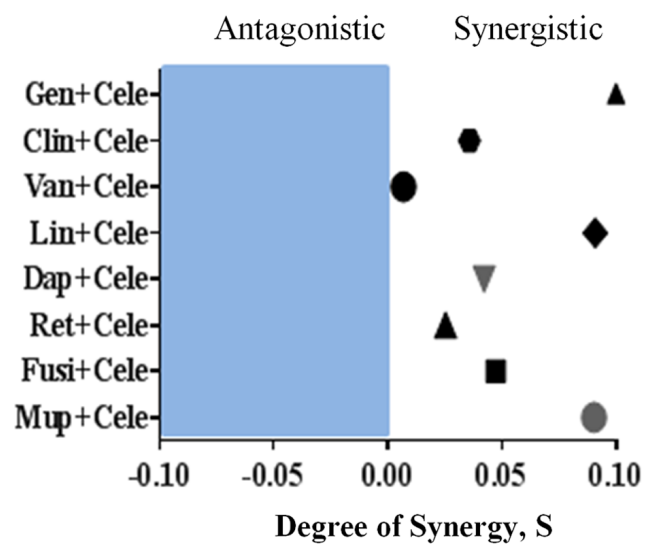

Linezolid-resistant $S$. aureus (NRS 119)

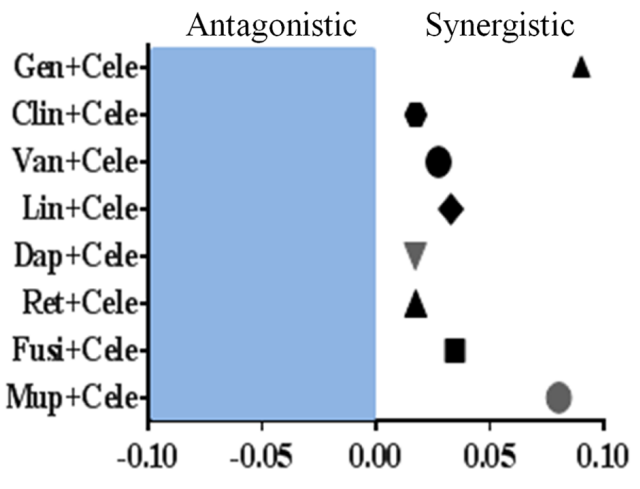

Degree of Synergy, $S$

\section{Mupirocin-resistant S. aureus (NRS 107)}

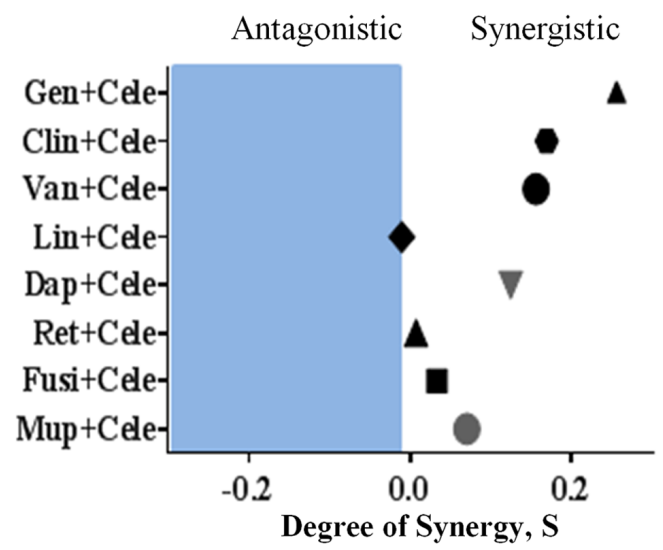

\section{Vancomycin-resistant S. aureus (VRSA 5)}

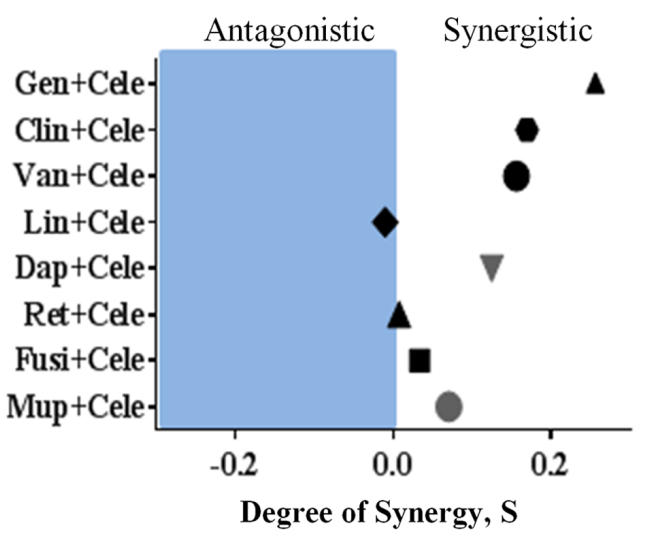

The degree of synergy was quantified after $12 \mathrm{~h}$ of treatment with celecoxib $(8 \mu \mathrm{g} / \mathrm{ml})$ in combination with sub-inhibitory concentrations of topical (mupirocin, fusidic acid, daptomycin, and retapamulin) and systemic antimicrobials (gentamicin, clindamycin, vancomycin, and linezolid).
Time kill kinetics of celecoxib against $S$. aureus revealed a unique biphasic killing pattern. The bactericidal effect of celecoxib lasted for only a short time, after which gradual regrowth of bacteria was noticed. This pattern of inhibition and regrowth was reported for some antibiotics such as azlocillin and tobramycin against $P$. aeruginosa (White et al., 1980; McFarland et al., 1994). We suspected that the regrowth might be due to resistant bacterial subpopulation but our attempts to isolate a stable mutants to celecoxib failed. Additionally, at high MIC, celecoxib tends to precipitate in the growth media which might attributed to the regrowth of bacteria.

The mechanism of celecoxib's broad-spectrum antibacterial activity remains unidentified. In our study, we found that celecoxib inhibited the synthesis of DNA, RNA, and protein at concentrations significantly below the MIC. Additionally, the disruption of lipid synthesis was evident at higher MIC concentration, whereas no significant effect was observed on the cell wall synthesis. These results indicate that perturbation of the lipid synthesis by celecoxib might be a secondary effect due to the early RNA and protein synthesis inhibition. The effect of celecoxib on multiple macromolecular synthesis pathways indicating that celecoxib may in fact have a complex mode of action that involves inhibition of multiple targets in S. aureus or it may disrupt general cellular energy metabolism. Further, we attempted to generate a $S$. aureus mutant that is resistant to celecoxib. No colonies resistant to celecoxib at three-, five-, or tenfold the MIC were detected. In addition, serial passage of $S$. aureus with sub-inhibitory concentration of celecoxib for 12 days did not result in mutants resistant to celecoxib. The potential inhibition of multiple bacterial enzymes and pathways by celecoxib may help explain our inability to isolate spontaneous celecoxib-resistant mutants. Future studies are warranted to identify the precise molecular target (s) of celecoxib.

In view of the broad spectrum antibacterial activity exhibited by celecoxib in vitro, we decided to investigate the in vivo 
antibacterial activity of celecoxib in animal models of MRSA infection. First we tested the efficacy in MRSA infected C. elegans. Whole animal model including $C$. elegans, provides a great platform for validating the in vivo efficacy of novel compounds (Alajlouni and Seleem, 2013; Rajamuthiah et al., 2015). In addition, C. elegans models enables simultaneous assessment of efficacy and toxicity of the tested drugs, reduces the associated cost of drug discovery and lowers the burden for extensive animal testing (Alajlouni and Seleem, 2013; Rajamuthiah et al., 2015). Our results indicates that celecoxib at 16 and $32 \mu \mathrm{g} / \mathrm{ml}$, which are concentrations without considerable toxicity to the host, significantly reduced the mean bacterial load (by 71 and $85 \%$, respectively) when compared with a control group $(P \leq 0.05)$. Celecoxib at $32 \mu \mathrm{g} / \mathrm{ml}$ had an effect on the mean bacterial count that was comparable to that of linezolid $(16 \mu \mathrm{g} / \mathrm{ml})$. Next, we moved forward to validate celecoxib's efficacy in a mouse model of MRSA infection. However, a high MIC that cannot be achieved systemically is a major impediment to the potential use of celecoxib as an antimicrobial agent. While the use of celecoxib to treat systemic bacterial infections is not currently possible, local application of celecoxib for treating/preventing bacterial infections in wounds is a novel application for this drug that holds considerable promise. Therefore we decided to test the activity of celecoxib in a topical MRSA skin infection model. Celecoxib 1 and $2 \%$ significantly reduced the bacterial load in the wounds (by 72 and $87 \%$, respectively) when compared with a control group $(P \leq 0.05)$.

However, staphylococcal skin infections and exotoxins secreted by $S$. aureus often induce excess host inflammatory cytokines, which in turn aggravate the pathogenesis of the disease (Montgomery et al., 2013; Sharma-Kuinkel et al., 2013).This aggravated inflammatory cascade is thought to play a greater role in the severity of $S$. aureus skin infections more than the size of the bacterial burden (Montgomery et al., 2013; SharmaKuinkel et al., 2013). Additionally, inflammation has been shown to delay healing and to result in increased scarring (Eming et al., 2007). Drugs with anti-inflammatory properties, especially those that inhibit pro-inflammatory cytokines such as IL- 6 and TNF- $\alpha$, would accelerate the healing of chronic wounds. (Tindall, 1999; Fournier and Philpott, 2005; McCormack, 2011; Kumar et al., 2013; Sharma-Kuinkel et al., 2013). Celecoxib, which is known to have anti-inflammatory activity, would potentially be able to limit the inflammatory process induced by MRSA infection. Therefore, we measured the inflammatory cytokines in MRSA lesions treated with celecoxib. Topical treatment with celecoxib $1 \%$ significantly $(P \leq 0.05)$ reduced levels of TNF- $\alpha$ and IL- $1 \beta$, while celecoxib $2 \%$ significantly $(P \leq 0.05)$ reduced the levels of all the inflammatory cytokines measured (IL-6, TNF- $\alpha$, IL-1 $\beta$, and MCP-1). This ability of celecoxib to dampen the inflammatory response might aid the healing of chronic wounds (Wallace and Stacey, 1998; Fournier and Philpott, 2005; Cowin et al., 2006; Jialal et al., 2007; Khanna et al., 2010; Donath, 2014). Celecoxib's recognized beneficial role in the wound healing process, reducing scar formation without disrupting reepithelization, is an added advantage for the treatment of bacterial skin infections (Wilgus et al., 2003).

With increased emergence of resistant strains of $S$. aureus to topical drugs of choice, such as mupirocin and fusidic acid, combination therapies have recently been gaining attention (Farrell et al., 2011; Huang et al., 2011; McNeil et al., 2011; Brynildsen et al., 2013; Hu and Coates, 2013; Mohammad et al., 2015). Identifying other antimicrobial partners capable of being paired with celecoxib can potentially prolong the clinical utility of these antibiotics and reduce the likelihood of emergence of resistant strains. We, therefore, investigated whether celecoxib has potential to be combined with antibiotics against multidrug-resistant $S$. aureus strains by using the Bliss independence model (Morones-Ramirez et al., 2013). Celecoxib was found to exhibit a synergistic relationship with topical (mupirocin, fusidic acid, daptomycin, and retapamulin) and systemic antimicrobials (gentamicin, clindamycin, vancomycin, and linezolid), against most of the tested multidrug-resistant staphylococcal strains, including MRSA300, NRS119, NRS107, and VRSA5. This finding provides a potential basis for the combination of celecoxib with conventional antimicrobial drugs for the treatment staphylococcal skin infections and reducing the likelihood of strains developing resistance to monotherapy. This combination therapy is also expected to overcome some of the limitations associated with celecoxib monotherapy through lowering the required therapeutic dose, though further in vivo studies are needed to confirm this point.

Taken together, our results show that celecoxib exhibits several beneficial properties, including broad spectrum antimicrobial activity against various multidrug resistant Gram-positive and Gram-negative pathogens, synergistic action with conventional antimicrobials, and anti-inflammatory activity that reduces excess host inflammation during infection. Celecoxib may, therefore, be a good candidate for repurposing for the treatment of topical bacterial infections. This emerging approach might form a novel alternative strategy in search of new antimicrobials.

\section{Author Contributions}

ST and WY performed animal experiments. MS designed the study. ST and MS analyzed data and wrote the manuscript. All authors discussed the results and commented on the manuscript.

\section{Acknowledgments}

We thank Dr. Alex O’Neill, University of Leeds, for providing Escherichia coli SM1411 $\Delta$ acrAB strain. The authors would like to thank the Network of Antimicrobial Resistance in Staphylococcus aureus (NARSA) program supported under NIAID/NIH Contract \# HHSN272200700055C for providing MRSA strains used in this study. We would like to thank BEI Resources, NIAID, NIH for providing Bacillus strains. 


\section{References}

Alajlouni, R. A., and Seleem, M. N. (2013). Targeting listeria monocytogenes rpoA and rpoD genes using peptide nucleic acids. Nucleic Acid Ther. 23, 363-367. doi: $10.1089 /$ nat.2013.0426

Annamanedi, M., and Kalle, A. M. (2014). Celecoxib sensitizes Staphylococcus aureus to antibiotics in macrophages by modulating SIRT1. PLoS ONE 9:e99285. doi: 10.1371/journal.pone.0099285

Aryee, A., and Price, N. (2015). Antimicrobial stewardship - can we afford to do without it? Br. J. Clin. Pharmacol. 79, 173-181. doi: 10.1111/bcp.12417

Ashburn, T. T., and Thor, K. B. (2004). Drug repositioning: identifying and developing new uses for existing drugs. Nat. Rev. Drug Discov. 3, 673-683. doi: $10.1038 /$ nrd1468

Bensen, W. G. (2000). Antiinflammatory and analgesic efficacy of COX-2 specific inhibition: from investigational trials to clinical experience. J. Rheumatol. Suppl. $60,17-24$.

Brynildsen, M. P., Winkler, J. A., Spina, C. S., Macdonald, I. C., and Collins, J. J. (2013). Potentiating antibacterial activity by predictably enhancing endogenous microbial ROS production. Nat. Biotechnol. 31, 160-165. doi: 10.1038/nbt.2458

Centers for Disease Control and Prevention [CDC] (ed.). (2013). Antibiotic Resistance Threats in the United States, 2013. Atlanta: CDC.

Chambers, H. F., and Deleo, F. R. (2009). Waves of resistance: Staphylococcus aureus in the antibiotic era. Nat. Rev. Microbiol. 7, 629-641. doi: $10.1038 /$ nrmicro2200

Chiu, H. C., Lee, S. L., Kapuriya, N., Wang, D., Chen, Y. R., Yu, S. L., et al. (2012). Development of novel antibacterial agents against methicillinresistant Staphylococcus aureus. Bioorg. Med. Chem. 20, 4653-4660. doi: 10.1016/j.bmc.2012.06.018

Chiu, H. C., Yang, J., Soni, S., Kulp, S. K., Gunn, J. S., Schlesinger, L. S., et al. (2009). Pharmacological exploitation of an off-target antibacterial effect of the cyclooxygenase-2 inhibitor celecoxib against Francisella tularensis. Antimicrob. Agents Chemother. 53, 2998-3002. doi: 10.1128/AAC. 00048-09

Cho, J. S., Pietras, E. M., Garcia, N. C., Ramos, R. I., Farzam, D. M., Monroe, H. R. et al. (2010). IL-17 is essential for host defense against cutaneous Staphylococcus aureus infection in mice. J. Clin. Invest. 120, 1762-1773. doi: 10.1172/JCI40891

Cho, J. S., Zussman, J., Donegan, N. P., Ramos, R. I., Garcia, N. C., Uslan, D. Z., et al. (2011). Noninvasive in vivo imaging to evaluate immune responses and antimicrobial therapy against Staphylococcus aureus and USA300 MRSA skin infections. J. Invest. Dermatol. 131, 907-915. doi: 10.1038/jid.2010.417

Chong, C. R., and Sullivan, D. J. (2007). New uses for old drugs. Nature 448, 645-646. doi: 10.1038/448645a

Cowin, A. J., Hatzirodos, N., Rigden, J., Fitridge, R., and Belford, D. A. (2006). Etanercept decreases tumor necrosis factor-alpha activity in chronic wound fluid. Wound Repair Regen. 14, 421-426. doi: 10.1111/j.1743-6109.2006.00141.x

Davis, S. L., Perri, M. B., Donabedian, S. M., Manierski, C., Singh, A., Vager, D., et al. (2007). Epidemiology and outcomes of community-associated methicillinresistant Staphylococcus aureus infection. J. Clin. Microbiol. 45, 1705-1711. doi: 10.1128/JCM.02311-06

Diep, B. A., Carleton, H. A., Chang, R. F., Sensabaugh, G. F., and PerdreauRemington, F. (2006). Roles of 34 virulence genes in the evolution of hospitaland community-associated strains of methicillin-resistant Staphylococcus aureus. J. Infect. Dis. 193, 1495-1503. doi: 10.1086/503777

Diep, B. A., Equils, O., Huang, D. B., and Gladue, R. (2012). Linezolid effects on bacterial toxin production and host immune response: review of the evidence. Curr. Ther. Res. Clin. Exp. 73, 86-102. doi: 10.1016/j.curtheres.2012.04.002

Dobie, D., and Gray, J. (2004). Fusidic acid resistance in Staphylococcus aureus. Arch. Dis. Child. 89, 74-77. doi: 10.1136/adc.2003.019695

Donath, M. Y. (2014). Targeting inflammation in the treatment of type 2 diabetes: time to start. Nat. Rev. Drug Discov. 13, 465-476. doi: 10.1038/nrd4275

Eming, S. A., Krieg, T., and Davidson, J. M. (2007). Inflammation in wound repair: molecular and cellular mechanisms. J. Invest. Dermatol. 127, 514-525. doi: 10.1038/sj.jid.5700701

Farrell, D. J., Castanheira, M., and Chopra, I. (2011). Characterization of global patterns and the genetics of fusidic acid resistance. Clin. Infect. Dis. 52(Suppl. 7), S487-S492. doi: 10.1093/cid/cir164

Fischbach, M. A., and Walsh, C. T. (2009). Antibiotics for emerging pathogens. Science 325, 1089-1093. doi: 10.1126/science.1176667
Fournier, B., and Philpott, D. J. (2005). Recognition of Staphylococcus aureus by the innate immune system. Clin. Microbiol. Rev. 18, 521-540. doi: 10.1128/CMR.18.3.521-540.2005

Frampton, J. E., and Keating, G. M. (2007). Celecoxib: a review of its use in the management of arthritis and acute pain. Drugs 67, 2433-2472. doi: 10.2165/00003495-200767160-00008

Gordon, R. J., and Lowy, F. D. (2008). Pathogenesis of methicillin-resistant Staphylococcus aureus infection. Clin. Infect. Dis. 46(Suppl. 5), S350-S359. doi: 10.1086/533591

Hu, Y., and Coates, A. R. (2013). Enhancement by novel anti-methicillin-resistant Staphylococcus aureus compound HT61 of the activity of neomycin, gentamicin, mupirocin and chlorhexidine: in vitro and in vivo studies. J. Antimicrob. Chemother. 68, 374-384. doi: 10.1093/jac/dks384

Huang, L., Dai, T., Xuan, Y., Tegos, G. P., and Hamblin, M. R. (2011). Synergistic combination of chitosan acetate with nanoparticle silver as a topical antimicrobial: efficacy against bacterial burn infections. Antimicrob. Agents Chemother. 55, 3432-3438. doi: 10.1128/AAC.01803-10

Jialal, I., Miguelino, E., Griffen, S. C., and Devaraj, S. (2007). Concomitant reduction of low-density lipoprotein-cholesterol and biomarkers of inflammation with low-dose simvastatin therapy in patients with type 1 diabetes. J. Clin. Endocrinol. Metab. 92, 3136-3140. doi: 10.1210/jc.2007-0453

Kalle, A. M., and Rizvi, A. (2011). Inhibition of bacterial multidrug resistance by celecoxib, a cyclooxygenase-2 inhibitor. Antimicrob. Agents Chemother. 55, 439-442. doi: 10.1128/AAC.00735-10

Khanna, S., Biswas, S., Shang, Y., Collard, E., Azad, A., Kauh, C., et al. (2010). Macrophage dysfunction impairs resolution of inflammation in the wounds of diabetic mice. PLoS ONE 5:e9539. doi: 10.1371/journal.pone.0009539

King, M. D., Humphrey, B. J., Wang, Y. F., Kourbatova, E. V., Ray, S. M., and Blumberg, H. M. (2006). Emergence of community-acquired methicillinresistant Staphylococcus aureus USA 300 clone as the predominant cause of skin and soft-tissue infections. Ann. Intern. Med. 144, 309-317. doi: 10.7326/00034819-144-5-200603070-00005

Kresken, M., Hafner, D., Schmitz, F. J., Wichelhaus, T. A., and Paul-EhrlichSociety For, C. (2004). Prevalence of mupirocin resistance in clinical isolates of Staphylococcus aureus and Staphylococcus epidermidis: results of the antimicrobial resistance surveillance study of the paul-ehrlich-society for chemotherapy, 2001. Int. J. Antimicrob. Agents 23, 577-581. doi: 10.1016/j.ijantimicag.2003.11.007

Kumar, V., Kaur, K., Gupta, G. K., Gupta, A. K., and Kumar, S. (2013). Developments in synthesis of the anti-inflammatory drug, celecoxib: a review. Recent Pat. Inflamm. Allergy Drug Discov. 7, 124-134. doi: 10.2174/1872213X11307020004

McCormack, P. L. (2011). Celecoxib: a review of its use for symptomatic relief in the treatment of osteoarthritis, rheumatoid arthritis and ankylosing spondylitis. Drugs 71, 2457-2489. doi: 10.2165/11208240-00000000000000

McFarland, M. M., Scott, E. M., and Li Wan Po, A. (1994). Time-survival studies for quantifying effects of azlocillin and tobramycin on Pseudomonas aeruginosa. Antimicrob. Agents Chemother. 38, 1271-1276. doi: 10.1128/AAC.38.6.1271

McNeil, J. C., Hulten, K. G., Kaplan, S. L., and Mason, E. O. (2011). Mupirocin resistance in Staphylococcus aureus causing recurrent skin and soft tissue infections in children. Antimicrob. Agents Chemother. 55, 2431-2433. doi: 10.1128/AAC.01587-10

Mohamed, M. F., Hamed, M. I., Panitch, A., and Seleem, M. N. (2014). Targeting Methicillin-Resistant Staphylococcus aureus with Short Salt-Resistant Synthetic Peptides. Antimicrob. Agents Chemother. 58, 4113-4122. doi: 10.1128/AAC.02578-14

Mohamed, M. F., and Seleem, M. N. (2014). Efficacy of short novel antimicrobial and anti-inflammatory peptides in a mouse model of methicillin-resistant Staphylococcus aureus (MRSA) skin infection. Drug Design Dev. Ther. 8, 19791983. doi: 10.2147/DDDT.S72129

Mohammad, H., Mayhoub, A. S., Cushman, M., and Seleem, M. N. (2015). Antibiofilm activity and synergism of novel thiazole compounds with glycopeptide antibiotics against multidrug-resistant Staphylococci. J. Antibiot. (Tokyo) 68, 259-266. doi: 10.1038/ja.2014.142

Montgomery, C. P., Daniels, M. D., Zhao, F., Spellberg, B., Chong, A. S., and Daum, R. S. (2013). Local inflammation exacerbates the severity of Staphylococcus aureus skin infection. PLoS ONE 8:e69508. doi: 10.1371/journal.pone.0069508 
Morones-Ramirez, J. R., Winkler, J. A., Spina, C. S., and Collins, J. J. (2013). Silver enhances antibiotic activity against gram-negative bacteria. Sci. Transl. Med. 5:190ra181. doi: 10.1126/scitranslmed.3006276

O’Neill, A. J., Bostock, J. M., Moita, A. M., and Chopra, I. (2002). Antimicrobial activity and mechanisms of resistance to cephalosporin $\mathrm{P} 1$, an antibiotic related to fusidic acid. J. Antimicrob. Chemother. 50, 839-848. doi: 10.1093/jac/dkf248

Okusu, H., Ma, D., and Nikaido, H. (1996). AcrAB efflux pump plays a major role in the antibiotic resistance phenotype of Escherichia coli multiple-antibioticresistance (Mar) mutants. J. Bacteriol. 178, 306-308.

Pereira, P. A., Trindade, B. C., Secatto, A., Nicolete, R., Peres-Buzalaf, C., Ramos, S. G., et al. (2013). Celecoxib improves host defense through prostaglandin inhibition during Histoplasma capsulatum infection. Mediators Inflamm. 2013:11. doi: 10.1155/2013/950981

Rajamuthiah, R., Fuchs, B. B., Conery, A. L., Kim, W., Jayamani, E., Kwon, B., et al. (2015). Repurposing salicylanilide anthelmintic drugs to combat drug resistant Staphylococcus aureus. PLoS ONE 10:e0124595. doi: 10.1371/journal.pone.0124595

Randall, C. P., Mariner, K. R., Chopra, I., and O'Neill, A. J. (2013). The target of daptomycin is absent from Escherichia coli and other gram-negative pathogens. Antimicrob. Agents Chemother. 57, 637-639. doi: 10.1128/AAC.02005-12

Rangel-Vega, A., Bernstein, L. R., Mandujano-Tinoco, E. A., Garcia-Contreras, S. J., and Garcia-Contreras, R. (2015). Drug repurposing as an alternative for the treatment of recalcitrant bacterial infections. Front. Microbiol. 6:282. doi: 10.3389/fmicb.2015.00282

Rioja, I., Bush, K. A., Buckton, J. B., Dickson, M. C., and Life, P. F. (2004). Joint cytokine quantification in two rodent arthritis models: kinetics of expression, correlation of mRNA and protein levels and response to prednisolone treatment. Clin. Exp. Immunol. 137, 65-73. doi: 10.1111/j.13652249.2004.02499.x

Seybold, U., Kourbatova, E. V., Johnson, J. G., Halvosa, S. J., Wang, Y. F., King, M. D., et al. (2006). Emergence of community-associated methicillinresistant Staphylococcus aureus USA300 genotype as a major cause of health care-associated blood stream infections. Clin. Infect. Dis. 42, 647-656. doi: $10.1086 / 499815$

Sharma-Kuinkel, B. K., Zhang, Y., Yan, Q., Ahn, S. H., Fowler, V. G. Jr. (2013). Host gene expression profiling and in vivo cytokine studies to characterize the role of linezolid and vancomycin in methicillin-resistant Staphylococcus aureus (MRSA) murine sepsis model. PLoS ONE 8:e60463. doi: 10.1371/journal.pone.0060463

Stryjewski, M. E., and Corey, G. R. (2014). Methicillin-resistant Staphylococcus aureus: an evolving pathogen. Clin. Infect. Dis. 58(Suppl. 1), S10-S19. doi: 10.1093/cid/cit613

Tattevin, P., Diep, B. A., Jula, M., and Perdreau-Remington, F. (2009). Methicillinresistant Staphylococcus aureus USA300 clone in long-term care facility. Emerg. Infect. Dis. 15, 953-955. doi: 10.3201/eid1506.080195

Tenover, F. C., and Goering, R. V. (2009). Methicillin-resistant Staphylococcus aureus strain USA300: origin and epidemiology. J. Antimicrob. Chemother. 64, 441-446. doi: 10.1093/jac/dkp241
Tenover, F. C., Mcallister, S., Fosheim, G., Mcdougal, L. K., Carey, R. B., Limbago, B., et al. (2008). Characterization of Staphylococcus aureus isolates from nasal cultures collected from individuals in the United States in 2001 to 2004. J. Clin. Microbiol. 46, 2837-2841. doi: 10.1128/JCM.00480-08

Thangamani, S., Mohammad, H., Younis, W., and Seleem, M. N. (2015). Drug repurposing for the treatment of Staphylococcal Infections. Curr. Pharm. Des. 21, 2089-2100. doi: 10.2174/1381612821666150310 104416

Tindall, E. (1999). Celecoxib for the treatment of pain and inflammation: the preclinical and clinical results. J. Am. Osteopath. Assoc. 99, S13-S17.

Tong, S. Y., Bishop, E. J., Lilliebridge, R. A., Cheng, A. C., Spasova-Penkova, Z., Holt, D. C., et al. (2009). Community-associated strains of methicillin-resistant Staphylococcus aureus and methicillin-susceptible S. aureus in indigenous Northern Australia: epidemiology and outcomes. J. Infect. Dis. 199, 1461-1470. doi: $10.1086 / 598218$

Vaara, M. (2010). Polymyxins and their novel derivatives. Curr. Opin. Microbiol. 13, 574-581. doi: 10.1016/j.mib.2010.09.002

Vaara, M., Siikanen, O., Apajalahti, J., Fox, J., Frimodt-Møller, N., He, H., et al. (2010). A novel polymyxin derivative that lacks the fatty acid tail and carries only three positive charges has strong synergism with agents excluded by the intact outer membrane. Antimicrob. Agents Chemother. 54, 3341-3346. doi: 10.1128/AAC.01439-09

Velkov, T., Deris, Z. Z., Huang, J. X., Azad, M. A., Butler, M., Sivanesan, S., et al. (2013). Surface changes and polymyxin interactions with a resistant strain of Klebsiella pneumoniae. Innate Immun. 20, 350-363. doi: $10.1177 / 1753425913493337$

Wallace, H. J., and Stacey, M. C. (1998). Levels of tumor necrosis factoralpha (TNF-alpha) and soluble TNF receptors in chronic venous leg ulcers-correlations to healing status. J. Invest. Dermatol. 110, 292-296. doi: 10.1046/j.1523-1747.1998.00113.x

White, A. R., Comber, K. R., and Sutherland, R. (1980). Comparative bactericidal effects of azlocillin and ticarcillin against Pseudomonas aeruginosa. Antimicrob. Agents Chemother. 18, 182-189. doi: 10.1128/AAC.18.1.182

Wilgus, T. A., Vodovotz, Y., Vittadini, E., Clubbs, E. A., and Oberyszyn, T. M. (2003). Reduction of scar formation in full-thickness wounds with topical celecoxib treatment. Wound Repair Regen. 11, 25-34. doi: 10.1046/j.1524475X.2003.11106.x

Conflict of Interest Statement: The authors declare that the research was conducted in the absence of any commercial or financial relationships that could be construed as a potential conflict of interest.

Copyright (C) 2015 Thangamani, Younis and Seleem. This is an open-access article distributed under the terms of the Creative Commons Attribution License (CC BY). The use, distribution or reproduction in other forums is permitted, provided the original author(s) or licensor are credited and that the original publication in this journal is cited, in accordance with accepted academic practice. No use, distribution or reproduction is permitted which does not comply with these terms. 